\title{
New Blade Profile of VAWT: Experimental and Analysis to Introduce It in Urban Cites
}

\author{
Aouachria Zeroual $^{1 *}$, Belalmi Rabab ${ }^{1}$, Haddad Louiza $^{2}$, Tighaza Sihem ${ }^{1}$ \\ ${ }^{1}$ Applied Energy Physics Laboratory (LPEA), University Batna, Batna 05000, Algeria \\ ${ }^{2}$ Laboratory of Natural Hazards and Territorial Planning (LARNAT), University Batna, Batna 05000, Algeria
}

Corresponding Author Email: zeroual.aouachria@univ-batna.dz

https://doi.org/10.18280/ijdne.160109

Received: 6 July 2020

Accepted: 27 December 2020

Keywords:
experimental analysis, Savonius rotor,
vibration isolation

experimental analysis, Savonius rotor, vibration isolation

\begin{abstract}
\end{abstract}
\section{INTRODUCTION}

During the last century, fossil and nuclear fuels were the most important energy resources for humankind. Because of some environmental problems such as global warming, acid rain, nuclear accidents, and marine pollution... etc., the need for alternative energy sources became important. The cleanest energy is the most interest field of many scientists and researchers [1-6]. At the end of 2007, more than $95 \mathrm{GW}$ were in service worldwide. They are mainly distributed as follows: in Germany $(22.2 \mathrm{GW})$, the United States (16.8 GW) and Spain $(15.5 \mathrm{GW})$ [7, 8]. The wind continued to be the major source of energy and is one of the most promising and potential alternatives of renewable energy. In addition, to growing economic attractiveness of the wind energy, there are more ecological arguments for its use: i. Wind-power plants emit absolutely no $\mathrm{CO}_{2}$, by far the major pollutant when fuels (other than hydrogen or biomass) are burned; ii. As do nuclear plants, the operation of wind turbine leaves behind no dangerous residues; iii. Decommissioning costs of wind turbines are much smaller than those of many other types of power plants, especially compared with those of nuclear generators and iv. Land occupied by wind farms can find other simultaneous uses such as in agriculture [9-14]. Several wind machine configurations, including: i. drag-type turbines; iiLift-type turbine; appear during the design and simulation of rotating equipment, especially when this equipment is in contact with a given fluid. Among these equipment's the wind turbine represents a device which can utilize the wind's kinetic energy to produce the mechanical or electrical energy [15-18]. The vertical axis wind rotor as another important kind wind turbine is a good choice for men average and small-scale wind power generation [19]. The use of wind turbines for smallscale and urban applications is a topic that is receiving increasing attention that because it adapts well to turbulent flows caused by the roughness of the urban field of urban areas. It has received, more and more attracts for its advantages of simple design, low cost, and good maintenance [20]. In addition, in urban areas the wind is very turbulent and unstable with fast changes in direction and velocity. On the one hand, experimental studies have reported on the Savonius rotors Newman et al. [21-23] and others. All studies investigated the effects of several geometrical parameters on the rotor performances. According to its design, a vertical axis wind turbine is submissive to asymmetric efforts at all times. One can show that these efforts increase with the machine rotation frequency $[24,25]$. Then at high speed the rotor is solicited by any great efforts. Furthermore, the effect of the clumsiness, inherent in its construction, generates vibrations which contribute to the risks of its destruction [26]. On the one hand, several reaches [27-32] have reported on experimental and theoretical studies on the Savonius rotors. These studies investigated the effects of several geometrical parameters on its performances. All these investigations are more or less unsatisfactory in most situations. They do not report the data or the information on the mechanical behaviour. In general, very few theoretical works on the analysis of the actual flow around the Savonius rotor are available. This is mainly due to the complexity of the fluid flow around this machine and the difficulty of its modelling. Several researches have commented that a reliable analysis of the flow around a Savonius rotor is extremely difficult if not possible [33]. Actually, other attempts to investigate the flow character [34] underline the extreme difficulty of the flow modelling. The results were more or less satisfactory.

To bypass these difficulties, a direct determination of the pressure field on the blade surface of the Savonius rotor, as a suitable approach leading to clear information on its functionality it is proposed. This idea was suggested by Aouachria et al. [27]. In the present work, a general model is adopted by taking into account a gap between the blades and the experimental instantaneous pressure field. Discuss both the reaction ( $\mathrm{RC}$ and $\mathrm{RD}$ ) obtained at the Savonius rotor supports, as well as the vibratory phenomena have analysed. This study 
is completed by an experimental analysis, primary of an adequate system of a suspension to avoid these vibrations and secondary by a modified the blade profile to improve the turbine efficiency and with the rotor fulfilling the same role from that of the electric generator simultaneously [35]. As the literature has not reported similar studies, these results cannot therefore be compared to other similar results; they provide information about the aero-dynamical and the mechanical functioning.

\section{EXPERIMENTAL STUDY}

\subsection{Instantaneous pressure measurements}

The Savonius rotor used is composed of two half cylindrical blades with a gap. The dimensions of this rotor are the following: $\mathrm{D}=100 \mathrm{~mm}, \mathrm{~h}=300 \mathrm{~mm}, \delta=25 \mathrm{~mm}$. At each extremity, the rotor is limited with a circular disc of $140 \mathrm{~mm}$ diameter. The pressure gauges are located into six circular holes of diameter $6.3 \mathrm{~mm}$ in the mid-plan of blade crosssection Figure 1a. The pressure gauges are piezoresistive type with thermal compensation according to the temperature range of the experiments figure.

The signal of the pressure received by the pressure transducer is so low that it requires an amplification at the upper flange of the wind turbine or even Figure 1c and Figure $2 \mathrm{~b}$. With the rotary contactors, it is transmitted to the external measuring chain see Figure $2 b$ and $1 c$. The rotation frequency is measured by a photo-diode system installed at the axis end of the rotor, (Figure 2a). Two sets of measurements have been performed for flow speeds of $10 \mathrm{~m} / \mathrm{s}$ and $12 \mathrm{~m} / \mathrm{s}$. Twelve instantaneous curves are obtained; six for intrados and six for extrados. Each measurement is performed for a complete rotation at the same frequency. The same method has been used for each of the twelve experiments. Thus, after the verification of the zero level of the gauge, the frequency and the pressure signals are registered simultaneously using a data acquisition system. Signals are also visualized on a memory oscilloscope. The signal treatment results, which are used to determine the support efforts, are not presented in this paper [18].

\subsection{Measurements of the instantaneous pressure field}

Signals pressures are also transmitted to a recording on a data acquisition card. They are thus stored on the memory BUFFER an HP1000 computer. Card HP12060 which allows simultaneous use of up to eight channels with a sampling frequency of $55 \mathrm{kHz} / \mathrm{n}$, where $\mathrm{n}$ is the number of service channels. It is this map we used. The recording time for each test was set to 5 seconds. The signals are stored in files, JBUF nomenclature by nomenclature IBUF blocks each having 128 points combining instantaneous pressure blade and the frequency signal. By means of the processing procedure "ECOD", which gives the conversion of JBUF data in real values, is treated hundred signal blocks four by four. This will include identifying distinct frequency signal tops pressure signals after ensuring for each test performed, the stability of the rotation frequency $\mathrm{N}$, and the balance of the Wheatstone bridge at the amplifier, frequency, and pressure signals, stored in the device data acquisition, were displayed on the storage oscilloscope. The latter was used to obtain a good determination of the period of the machine during a measurement. It was more difficult during the same series of tests at $\mathrm{U}_{\infty}$ fixed; realize the identity of the rotation speeds. Frequency fluctuations between these measures, however, did not exceed $6 \%$ the average value used. The relative error on $\mathrm{U} \infty$ is negligible (less $1 \%$ ). This results in a relative error of the same importance on the value of the peripheral speed ratio $\lambda$ and the frequency N. $\lambda$ is defined by: $\lambda=\omega .(R+r) / U \infty$. Where, $\omega$ represents the angular speed, $\mathrm{R}$ the radius of the blade and $(\mathrm{R}+\mathrm{r})$ the gyration radius of the blade tip.

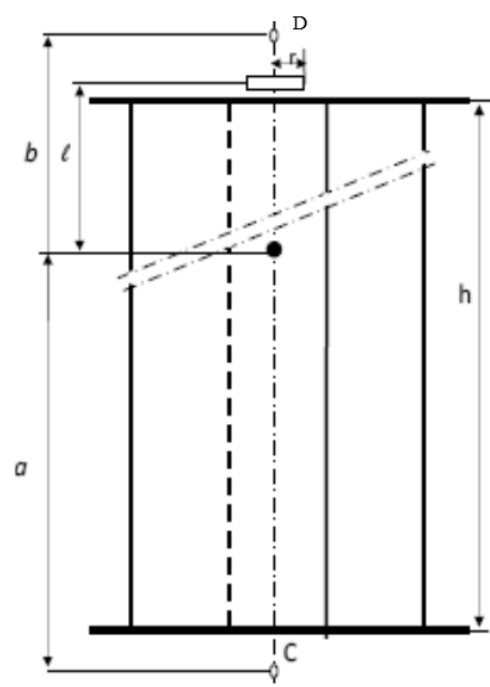

a. Savonius rotor

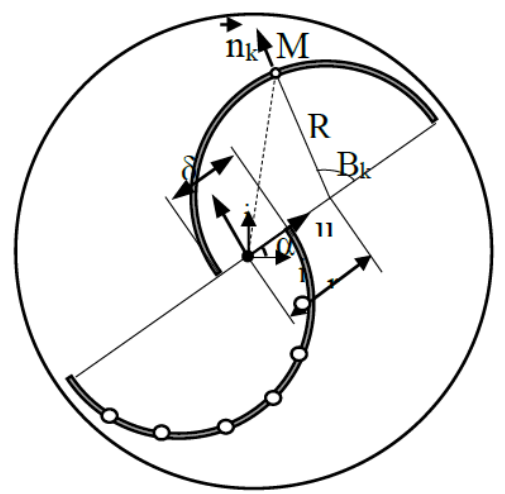

b. Cross section showing the location of the pressure sensors on the blades

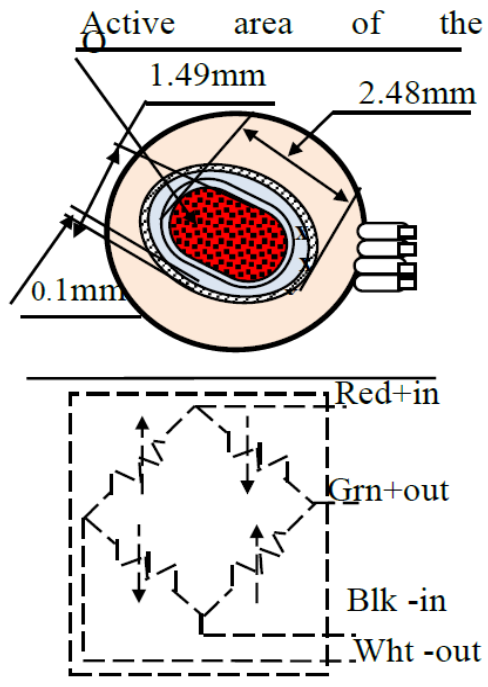

c. Signal amplificatory

Figure 1. Schematic diagrams of appartus 


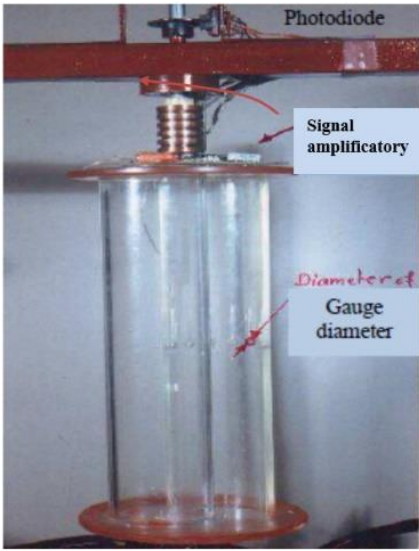

$\mathrm{a}$

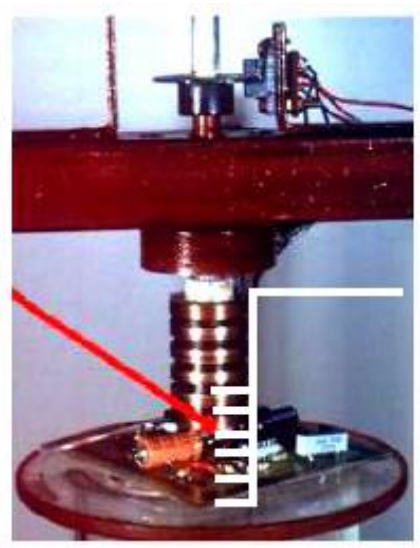

b
Figure 2. (a) Test stand; (b) rotating contactors and amplificatory

\section{UPPORT EFFORTS}

\subsection{Vibration phenomena}

The objective is, here, to determine the support reactions and at each instant and to deduce their evolution with incidence. These efforts are associated to the strength of lift and drag. It is recorded when the calculation is performed in the fixed riper $(\mathrm{O}, \vec{\imath}, \vec{\jmath})$ see Figure $1 \mathrm{~b}$.

The computation model proposed is a generalization of twodimensional model and assumptions are the following: the flow is supposed incompressible fluid with a two-dimensional character. Then the calculation is carried out in a plan of the machine right section. The blade profiles are assimilated to two half circle with a neglected thickness and with a gap $\delta$ between them.The contacts support-axis are supposed with non-scarping. The forces that intervene are respectively: i-the actions of contact and which act on the supports $\mathrm{C}$ and $\mathrm{D}$, iithe braking forces on the rings adjusted in a way to fix the machine rotation regime for any flow velocity.

These forces represent then a load, iii-The aerodynamic forces, which are normalness on every point, to the blade elements. These forces are obtained by integrating the instantaneous pressures over the blade surface Eq. (15), iv- the machine weight. The different geometric parameters used in the calculus are mentioned on the schematic diagram Figure 1; then we consider: the direct orthonormal trihedron which is fixed $(\mathrm{O}, \vec{l}, \vec{\jmath}, \vec{k})$; where $\mathrm{O}$ is the mass center of machine supposed in equilibrium state. The direct orthonormal trihedron $(\mathrm{O}, \vec{u}, \vec{v}, \vec{k})$ linked to the machine, and is deducted from the previous riper by a rotation around the axis with angle $\alpha(\mathrm{t})=(\vec{\imath}, \vec{u}) . \mathrm{J}_{\mathbf{o}}$ represents the inertial operator in origin $\mathrm{O}$ of the priper and $\vec{\Omega}=\bar{\alpha} \vec{k}$ is the instantaneous rotation vector and I is the machine inertial moment. Finally $\vec{\nabla}=J_{0}(\Omega)$ is the kinetic moment of the system. The mass center theorem gives:

$$
\sum_{i \in(A+B)} \vec{F}_{k}+\vec{F}_{f}+\vec{R}_{C}+\vec{R}_{D}+\vec{P}=\vec{O}
$$

The kinetic theorem moment gives also:

$$
\frac{d \vec{\nabla}_{o}}{d t}=I \dot{\alpha} \vec{k}=\vec{M}_{o}^{t o t}
$$

We obtain, after all calculus, the total moment expression:

$$
\vec{M}_{o}=r R h \vec{k} \sum_{i \in(A+B)}\left(\Delta P_{k}^{A}+\Delta P_{k}^{B}\right) \sin \left(\beta_{k}\right) \Delta \beta_{k}
$$

Furthermore, we can write:

$$
\begin{gathered}
\overleftarrow{R}_{C}=X_{C} \vec{i}+Y_{C} \vec{j}+Z_{C} \vec{k} \\
\tilde{R}_{D}=X_{D} \vec{i}+Y_{D} \vec{j}+Z_{D} \vec{k}
\end{gathered}
$$

When we project the Eq. (1) on the two directions and and taking into consideration the relations (4) and (5) we obtain simultaneously:

$$
\sum_{i \in(A+B)} \vec{F}_{k} \vec{i}+N+X_{C}+X_{D}=0
$$

$$
\sum_{i \in(A+B)} \vec{F}_{k} \cdot \vec{j}+T+Y_{C}+Y_{D}=0
$$

With:

$$
\vec{F}_{f}=N \vec{i}+\overrightarrow{T j}
$$

with $f$ is the scrap coefficient. Moreover, on the direction, $\vec{k}$ we have:

$$
Z_{C}+Z_{D}-m g=O
$$

$$
\begin{aligned}
& r R h \sum_{i \in(A+B)}\left(\Delta P_{k}^{A}+\Delta P_{k}^{B}\right) \sin \left(\beta_{k}\right) \Delta \beta_{k}-r_{0} T=O \\
& b X_{D}-a X_{C}+l N_{F}=O \\
& a Y_{C}-b Y_{D}-l T=O
\end{aligned}
$$

The resolution of the system (10) associated to (6) and (7) gives the expression of $R_{C}\left(X_{C}, Y_{D}\right)$ and $R_{D}\left(X_{D}, Y_{D}\right)$; we have respectively:

$$
\begin{gathered}
X_{C}=\left[\frac{(l-b)}{(a+b)}\right] \cdot \frac{T}{f}-\frac{b}{(a+b)} \cdot \sum_{i \in(A+B)} \vec{F}_{k} \cdot \vec{i} \\
Y_{C}=\left[\frac{(l-b)}{(a+b)}\right] \cdot T-\frac{b}{(a+b)} \cdot \sum_{i \in(A+B)} \vec{F}_{k} \vec{j} \\
X_{D}=-\left[\frac{(l+a)}{(a+b)}\right] \cdot \frac{T}{f}-\frac{a}{(a+b)} \cdot \sum_{i \in(A+B)} \vec{F}_{k} \cdot \vec{i} \\
Y_{D}=-\left[\frac{(l+a)}{(a+b)}\right] \cdot T-\frac{a}{(a+b)} \cdot \sum_{i \in(A+B)} \vec{F}_{k} \cdot \vec{j}
\end{gathered}
$$

The Eq. (9) which gives the vertical reaction is not coupled 
with the others equations then it has not influence on the others reaction compoments. However we can note that if one supposes that the lower support is the only porter and the upper acts as a guide role, thus $\mathrm{Z}_{\mathrm{C}}=\mathrm{mg}$ and $\mathrm{Z}_{\mathrm{D}}=$ zero. We compute the Eqns. (11), (12), (13) and (14) in function of incidence $\alpha$ and the different parameters are: $a=204 \mathrm{~mm}, \mathrm{~b}=264 \mathrm{~mm}, \ell$ $=210 \mathrm{~mm}, \mathrm{r}_{0}=15 \mathrm{~mm}$, and $\mathrm{T}$ is calculated through the last equation of the system (10), to put in the difference pressure data. Results are plotted in the Figure 3, 4, 5 and 6.

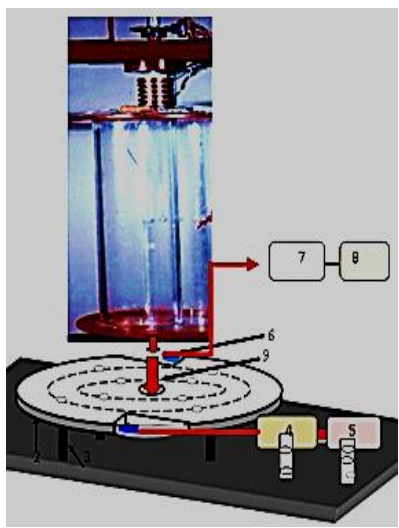

a

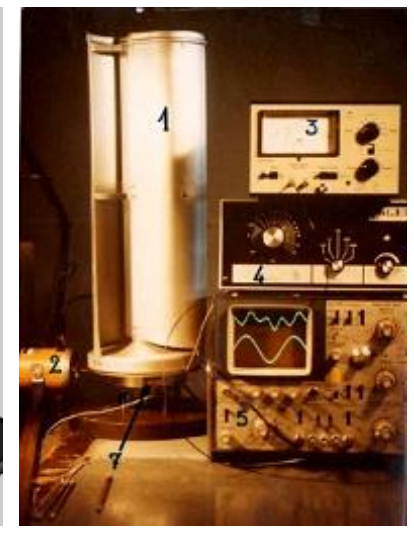

b
1. Tubine, 2.Vibrated pot, 3. Vibration measurement, 4. Frequency generator, 5. Oscilloscope, 6. Stems of the suspension, 7. Accelerometer captor

Figure 3. Schematic principle
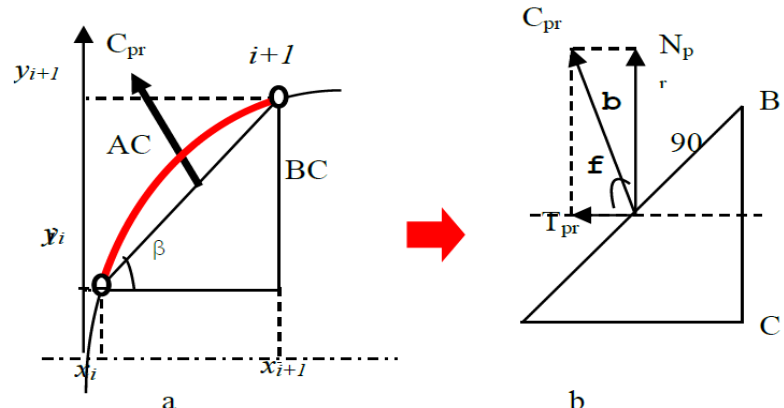

b

Figure 4. Pressure coefficient acting on the blade surface

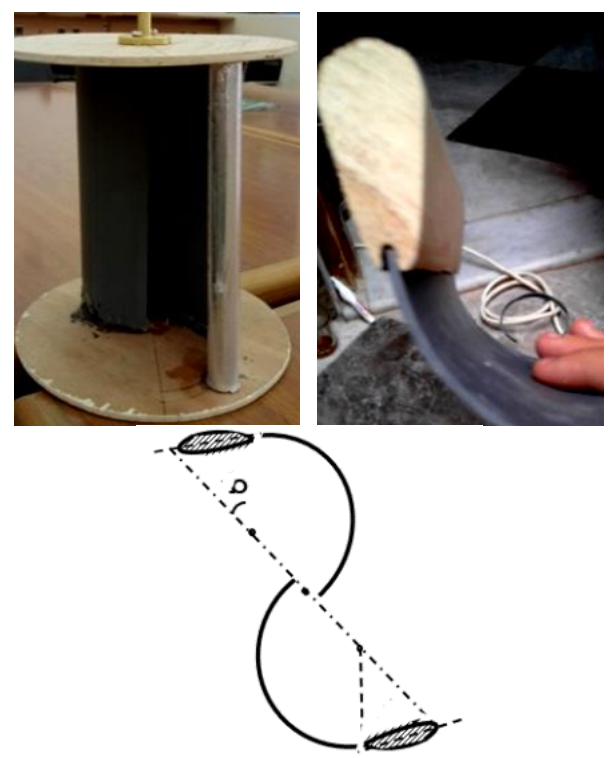

Figure 5. Modified model with blade tip in the form of aerodynamic profile NACA0012

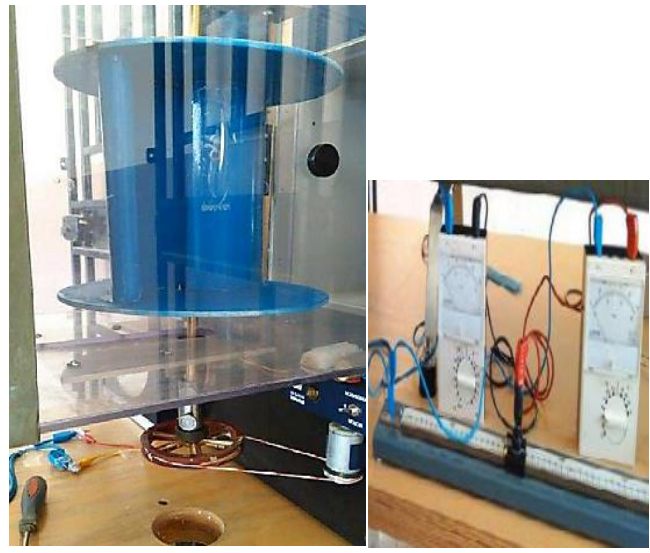

Figure 6. Wind blower mount coupled by the belt to a generator connected to the electrical circuit

\subsection{Study of vibration isolation}

The aim is to determine the dynamic characteristics of the suspension (eigenfrequency $\mathrm{f}_{0}$ and reduced damping factor a) in order to calculate the insulation factor $I_{a}(u)$ and to check whether the proposed suspension isolates the wind turbine well. We have simulated the efforts due to the vibrations by means of a vibrating pot, which acts on the basis at the height of the link disc in Figure 3. A low frequency generator, L F, permits to vary the excitation frequency ant its magnitude. Its reply is measured by an accelerometer captor and transmitted to a vibration measurement. This assembly makes it possible to determine the insulation factor, $\mathrm{I}_{\mathrm{a}}(\mathrm{u})$, which expresses the ratio of the forces transmitted to the rigid plinth with and without suspension. The parameter, a, is a reduced parameter that we determine by passer-by band method at the oscilloscope. This assembly type, on the stilts, shows two vibration types. On one side, a translation mode of frequency $\left(\mathrm{f}_{\mathrm{ot}}\right)$ makes the system oscillate in block parallel to horizontal plane and on the other side, a rotation vibration mode $\left(f_{\text {or }}\right)$ during which, the system oscillates around the rotor axis. We have tested three sets of four metallic stems of length 1 and diameter $\Phi$ noted. These stems are fixed at a distance of $R=5$ $\mathrm{cm}$ to the centre of the disc.

\section{MODIFIED ROTOR STUDY}

In order to make the comparison, two models were made. The first is conventional; Secondly, the model innovation lies in the integration of an aerodynamic profile on the outer ends of the two blades (see Figure $3 \mathrm{~b}$ ). Indeed, the behaviour of the blade profile with respect to the wind when the wind turbine is stopped causing a startup problem. Therefore, dynamic stall behaviour, air separation and other aerodynamic disturbances must be considered. The proposed methodology is based on researching a close relationship between the surface of the blade and the flow of the wind. The pressure coefficient, $\mathrm{Cpr}$, which describes the relative pressure across a flow field is closely correlated to the velocity at any point in the flow field. To study Cpr around the surface of the blade profile, on the one hand it is necessary to divide it into segments, as illustrated in the Figure 3 a and then calculate $\mathrm{Cpr}$ for each segment.

In the triangle formed by the segment $\mathrm{AB}$ with respect to the $\mathrm{x}$ and $\mathrm{y}$ axis, $\mathrm{BC}$ represents the opposite side and $\mathrm{AC}$ represents the adjacent side and 


$$
\begin{array}{cc}
A C=x_{i+1}-x_{i} & \\
B C=y_{i+1}-y_{i} & \text { for upper surface } \\
B C=y_{i}-y_{i+1} & \text { for lower surface }
\end{array}
$$

When BC is positive, the surface is oriented in the direction of rotation of the rotor, wheres when it is negative the segment is oriented in the opposite direction. The expression of the length of the elementary segment will be:

$$
A B=\sqrt{A C^{2}+|B C|^{2}}
$$

Having the coefficient of pressure exerted on each segment, we must use its tangential and normal contributions which are presented in Figure $4 \mathrm{~b}$ where we notice that the angle $\varphi=\pi / 2$ b. The contributions of this coefficient are given by:

$$
\begin{gathered}
\left\{\begin{array}{l}
T_{p r}=C_{p r} \sin (\varphi) \cdot s \quad B C \geq 0 \\
N_{p r}=C_{p f} \sin (\varphi) \cdot A B \quad \text { up-surface }
\end{array}\right. \\
\left\{\begin{array}{l}
T_{p r}=-C_{p r} \cos (\varphi) \cdot A B \quad B C \prec 0 \\
N_{p r}=C_{p f} \sin (\varphi) \cdot s \text { low-surface }
\end{array}\right.
\end{gathered}
$$

These equations clearly show the relation between Cpr, Tpr, $\mathrm{Npr}, \varphi$ and $\mathrm{AB}$ which are the generators of the mechanical performance of a body in a flow. The knowledge of the pressure coefficient tells us about the contribution of the drag and therefore it is possible to see the blade profile defined by the segments that suffer from drag forces. Electric measurement board $\varpi$ with the Sterling Phywe engine generator (04372.01) is used. Initially placing the wind turbine in the wind tunnel and connecting it to a closed electrical circuit. We started the tests with this generator that delivers a maximum voltage of $12 \mathrm{~V}$. It was fixed so that its pulley adjusts to the same level as the pulley coupled to the wind turbine. As regards the belt, it is necessary to use a trick to accomplish the clamping of the two pulleys, in order to minimize the eccentricity of the shafts, friction and prevent slippage thereof. A stroboscope was used to measure the rotation speed $\omega$ of the wind turbine Figure 8. Finally, the blower was turned on and the values of the parameters to be measured on a board were recorded. To obtain the curve of the power coefficient, the speed of the wind was first fixed at $5 \mathrm{~m}$ / $\mathrm{s}$, and $10 \mathrm{~m} / \mathrm{s}$ calculations were launched with different speed ratios (lambda) or with speed of rotation varying from 64.3 to 107.4 turn / s.

\section{RESULTS AND DISCUSSION}

An analysis of the expressions (12), (13), (14) and (15) shows that the rotor supports are solicited by periodic aerodynamic strengths, which generate vibration effects with the same frequency of that of the aerodynamic strengths. For a given regime, we record that the rotor support efforts are shared out between $\mathrm{C}$ and $\mathrm{D}$ in function of geometrical parameters defined by the machine dimensions ratios $\left(\frac{a}{a+b}, \frac{b}{a+b}, \frac{l+a}{a+b}, \frac{l-b}{a+b}\right)$ and also in function of the braking and aerodynamic forces. Accordingly, the rotor supports are solicited by the periodic efforts which come to cause the vibration effects with the same frequency, of that of aerodynamic forces. We can also note that if the assembly is symmetrical $(a=b)$, the drag and lift forces are compensated in a report equal to $1 / 2$ in each support $C$ and $D$. The effect of the braking force remains distributed between them in the dissymmetrical way. On the other hand, if the braking mode is a "couple axial" type, the components of the reactions $\mathrm{R}_{\mathrm{C}}$ and $\mathrm{R}_{\mathrm{D}}$ are only reduced to the drag and lift forces. We record that the contributions of braking terms are the predominant over the aerodynamic forces (Figure $8 \mathrm{a}$ and $8 \mathrm{~b}$ and $9 \mathrm{a}$ and $9 \mathrm{~b}$ ). When $U \infty=10 \mathrm{~m} / \mathrm{s}$ and $\lambda=0.2$ : in general, the reaction, $\vec{R}_{C}$ of the support $\mathrm{C}$, evolves in the 3rd riper quadrant of the trigonometric circle when incidence $\alpha$ is in the interval $\left(0^{\circ}, 60^{\circ}\right)$ and in the rest of the incidence range, its evolution is in the second riper quadrant of the trigonometric circle Figure 6, Figure 7.
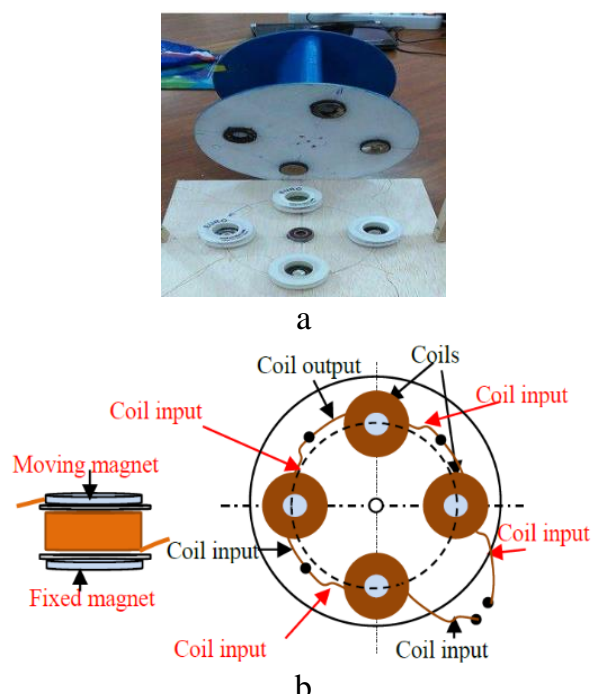

b

Figure 7. a)- Model, b)- wind turbine and common rotor generator diagram

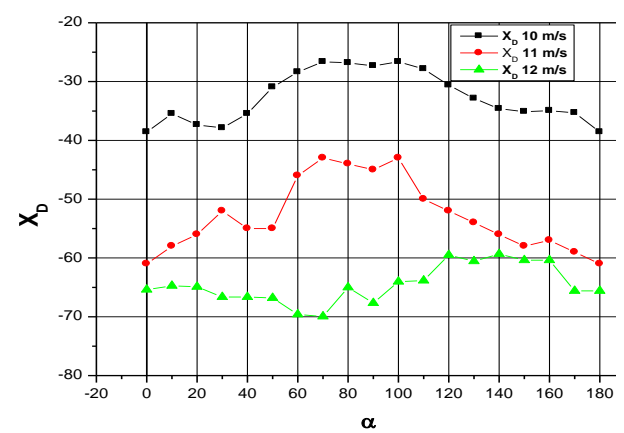

a

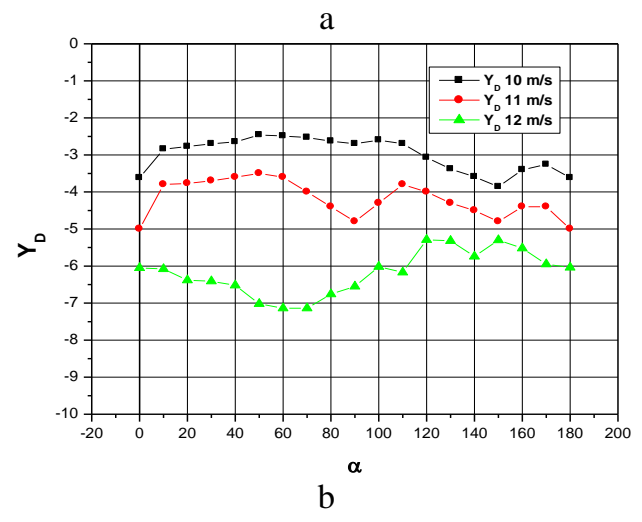

Figure 8. Component $X_{D}$ and $Y_{D}$ of $R_{D}$ 

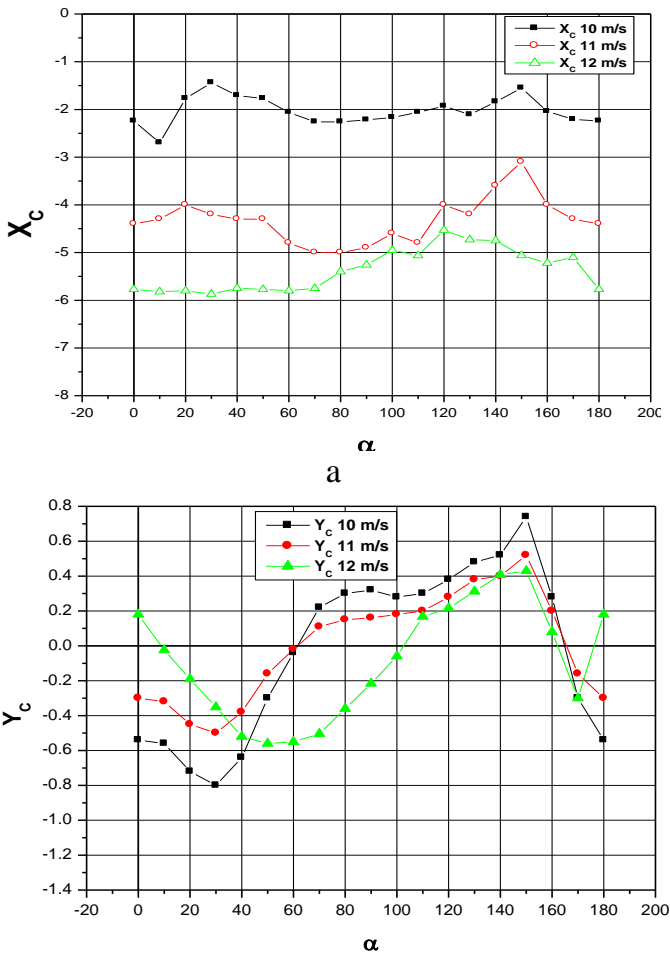

$\mathrm{b}$

Figure 9. Component $\mathrm{X}_{\mathrm{C}}$ and $\mathrm{Y}_{\mathrm{C}}$ of $\mathrm{R}_{\mathrm{C}}$

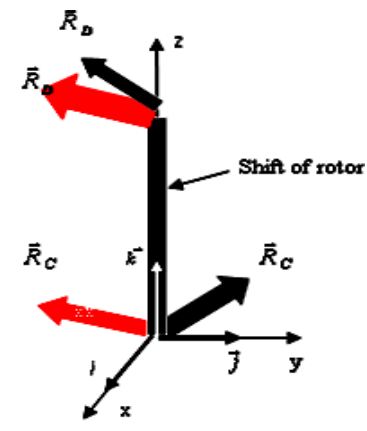

Figure 10. Reactions on supports and their average direction

As $\mathrm{X}_{\mathrm{D}}$ and $\mathrm{Y}_{\mathrm{D}}$ are always negative, the reaction $\vec{R}_{D}$, of the support $\mathrm{D}$, is in permanence in the second riper quadrant Figure 8 . Then we shall attend, in general, an effect vibration in the orthogonal plans to the 3rd riper quadrant for the incidence range $\alpha\left(0^{\circ}, 60^{\circ}\right)$ and a combination of vibrations resulting from a couple effect in the plan $(\vec{j}, \vec{k})$ and an effort in the direction $\vec{i}$ (Figure 10). When the rotor works in the second sector of the range incidence, it is submissive to a combination of vibrations result of a couple effect in the plan $(\vec{j}, \vec{k})$ and an effort in the direction $\vec{i}$ (Figure 10). When U⿻ $=12.5 \mathrm{~m} / \mathrm{s}$ and $\lambda=0.43$; we have the vibration phenomena consists to a couple effect in the plan $(\vec{j}, \vec{k})$.

The Table 1, below, provides the own frequencies $f_{o}$ and the lower limits $D_{f}$ of the frequency domains for a desirable isolation.

Table 1. The frequency domain limits for desirable isolation

\begin{tabular}{cccccccc}
\hline \multirow{2}{*}{$\boldsymbol{\Phi}_{\mathbf{L}}{ }^{\varphi}$} & $\boldsymbol{\varphi}$ & 5 & 5 & 5 & 3 & 3 & 3 \\
\cline { 2 - 8 } & $\mathbf{L}$ & 100 & 80 & 50 & 100 & 80 & 30 \\
\hline $\mathbf{f}_{\mathbf{0}}$ & 36 & 61 & 102 & 21 & 25 & 105 \\
$\mathbf{D}_{\mathbf{f}}$ & 55.9 & 85 & 144 & 29.7 & 36.5 & 148.5 \\
\hline
\end{tabular}

It appears that the set $\mathrm{J}_{100^{3}}$ permits to isolate the machine on large range of frequencies. The tip speed ratios given by $\lambda=\frac{2 \pi f d}{U_{\infty}}$ which varies on the incidence range $[0 ; 0.9]$ where $\mathrm{f}$ is the rotation frequency, $d$ the gyration radius of the tip blade and $\mathrm{U}_{\infty}$ is the wind speed. The maximal power coefficient, which we have measured in a wind tunnel corresponds to $\lambda=0.65$. It appears that the superior frequencies to $30 \mathrm{~Hz}$; correspond to flow velocities superior than $27.5 \mathrm{~m} / \mathrm{s}$. This is significant as the suspension J3100, Figure 11 can efficiently isolate the wind turbine against the tempest and blow wind risks for the high against the tempest and blow wind risks for the high regimes. Note that for low regimes the isolation in vibrations is not necessary because the effort magnitudes go slight (Figure 11).

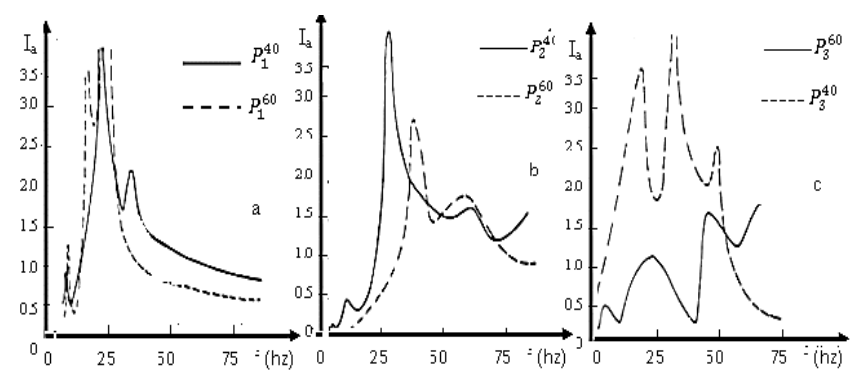

Figure 11. Insulation factor of the three suspensions $\boldsymbol{P}_{i}^{r}$

\subsection{New model study}

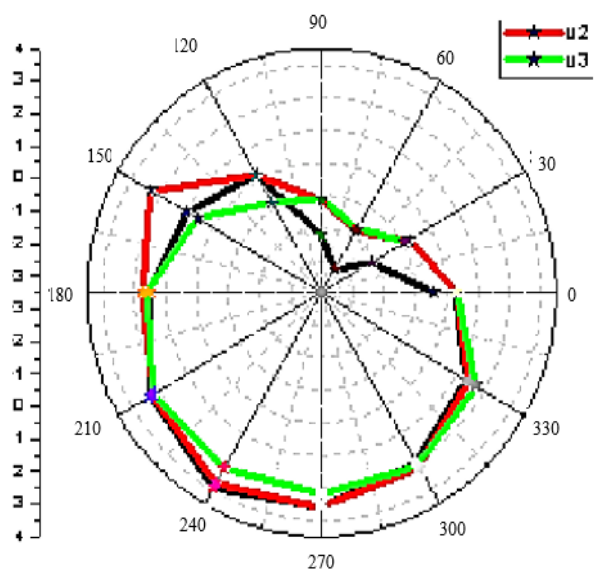

a

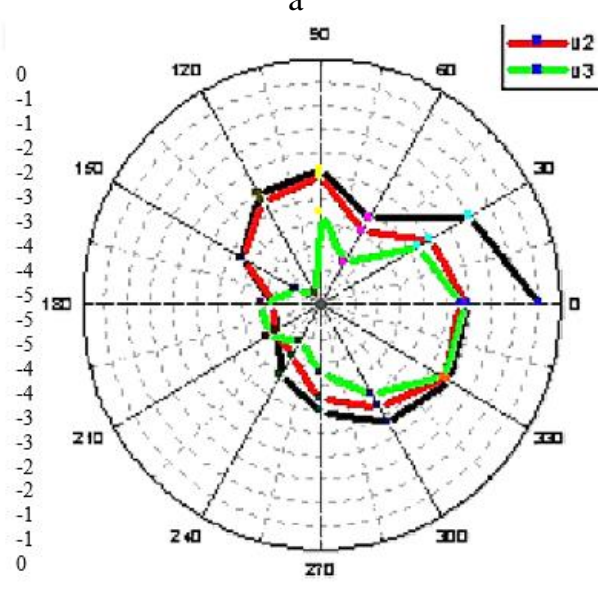

b

Figure 12. Evolution of the lift and the drag according to angle of incidence for different wind speeds 


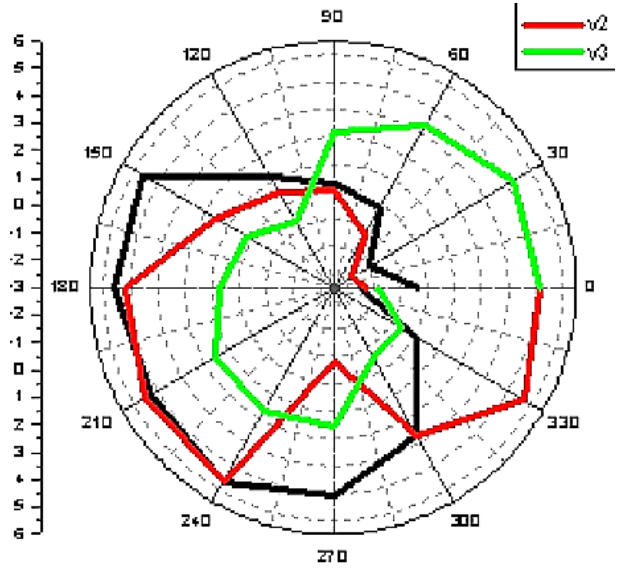

a

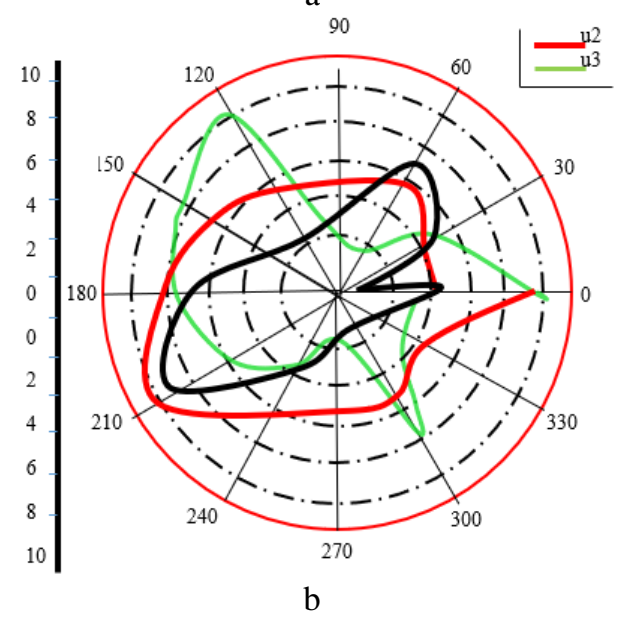

b

Figure 13. Lift and drag evolution vs incidence angles for different wind speeds

Figures 12 and 13 represents the evaluation of the drag as a function of the angle of incidence for different wind speeds. It shows that the drag has significant fluctuations over the range of angles of incidence from $0^{\circ}$ to $120^{\circ}$, then begins to increase monotonously with increasing wind speed. If we look closer we see that the drag is never zero, the rotor still offers resistance against the air regardless of the angle of incidence. This justifies the name "drag wind turbine" given to Savonius in the literature, because it is claimed that it is the differential drag between the concave and convex portion that causes rotation of the wind turbine This graph shows the evolution of the lift for different wind speeds, it is noted that is negative over the whole range of incidence angle, and it is seen in absolute value with the increase in speed of the said Magnus effect was highlighted by an experimental study by Agarwal et al. [7]. Note in Figure 9a that the impact of the high speed on the lift is more nuanced when the speed increases than the low speed. This impact represents a high rotational instability in the major range of incidence, on the other hand it is less nuanced over the rest of the range at least for a small interval or we feel a fluctuation of the drag force between $5 \pi / 32 \pi$ ]. Overall the drag is more uniform than the lift that's why we sometimes attribute the operation of this type of wind turbine to the drag.

\section{CONCLUSION}

The Savonius rotor is acting by coupled vibrations associated to the aerodynamic and clumsiness efforts. The vibrations, which are generated in the supports of the Savonius rotor by the aerodynamic strengths, have double the frequency than that of the machine. The best distribution of efforts between the supports can be obtained with a symmetrical mounting. The product design of the rotor may be the most possible equilibrium to reduce the clumsiness efforts. It may have an anti-vibratory system which acts at a high speed. A suspension on stilts can isolate our machine in high regimes. In the conclusion of this study, it can be seen that the thickening of the leading edges that the renovated wind turbine appears more loaded. The contribution of the lift is significant compared to the conventional rotor. It should also be noted that this contribution generates the Magnus phenomenon which contributes to the motor torque.

An easy way to comply with the conference paper formatting requirements is to use this document as a template and simply type your text into it.

\section{REFERENCES}

[1] Ahmed, M.R., Faizal, M., Lee, Y.H. (2013). Optimization of blade curvature and inter-rotor spacing of Savonius rotors for maximum wave energy extraction. Ocean Engineering, 65: 32-38. http://doi.org/10.1016/j.oceaneng.2013.02.005

[2] Mohamed, M.H., Janiga, G., Pap, E., Thévenin, D. (2011). Optimal blade shape of a modified Savonius turbine using an obstacle shielding the returning blade. Energy Conversion and Management, 52(1): 236-242. http://doi.org/10.1016/j.enconman.2010.06.070

[3] Jacobson, A., Kammen, D.M. (2007). Engineering, institutions, and the public interest: Evaluating product quality in the kenyan solar photovoltaic's industry. Energy Policy, 35(5): 2960-2968. http://dx.doi.org/10.1016/j.enpol.2006.10.024

[4] Lehr, U., Nitsch, J., Kratzat, M., Lutz, C., Edler, D. (2008). Renewable energy and employment in Germany. Energy Policy, 36(1): 108-117. http://doi.org/10.1016/j.enpol.2007.09.004

[5] Chalk, S.G., Miller, J.F. (2006). Key challenges and recent progress in batteries, fuel cells, and hydrogen storage for clean energy systems. Journal of Power Sources, $\quad 159(1)$ : $13-80$. https://doi.org/10.1016/j.jpowsour.2006.04.058

[6] Sumathi, S., Chai, S.P., Mohamed, A.R. (2008). Utilization of oil palm as a source of renewable energy in Malaysia. Renewable and Sustainable Energy Reviews, 12(9): 2404-2421. http://dx.doi.org/10.1016/j.rser.2007.06.006

[7] Agarwal, R., Karahanna, E. (2000). Time flies when you're having fun: Cognitive absorption and beliefs about information technology usage. AIS Quarterly, 24(4): 665-694. http://dx.doi.org/10.2307/3250951

[8] Rosa, A.V. (2000). Fundamentals of Renewable Energy Processes. Elsevier Inc., Second Edition.

[9] Nelson, R., Howden, M., Smith, M.S. (2008). Using adaptive governance to rethink the way science supports Australian drought policy. Environ. Sci. Policy, 11(7): 588-601. https://doi.org/10.1016/j.envsci.2008.06.005

[10] Vaughn, M.G., Shook, J.J., McMillen, J.C. (2008). Aging out of foster care and legal involvement: Toward a typology of risk. Social Service Review, 82(3): 419446. https://doi.org/10.1086/592535 
[11] Kennedy, S.W. (2005). Wind power planning: Assessing long-term costs and benefits. Energy Policy, 33(13): 1661-1675. https://doi.org/10.1016/j.enpol.2004.02.004

[12] Manwell, J.F., McGowan, J.G. (2009). Wind Energy Explained, Theory, Design and Application. Second Edition, John Wiley \& Sons Ltd.

[13] Hoffert, M.I, Caldeira, K., Benford, G., et al. (2002). Advanced technology paths to global climate stability: Energy for a greenhouse planet. Science, 298(5595): 981-987. https://doi.org/10.1126/science.1072357

[14] Vanek, F.M., Albright, L.D. (2008). Energy Systems Engineering: Evaluation and Implementation. Third edition. McGraw Hill, New York.

[15] Nahas, M.N., Mohamed, A.S., Akyurt, M., Kalaym, A.K. (1987). Wind energy: An engineering survey. Energy Sources, $\quad 9(3)$ : $137-148$. https://doi.org/10.1080/00908318708908691

[16] Nahas, M.N., Akyurt, M. (1992). Performance prediction for windmills with linkage-guided blades. Energy Sources, 14(1): https://doi.org/10.1080/00908319208908705

[17] Aouachria, Z. (1987). Eolienne Savonius: Comportements mécanique et aérodynamique, thèse de doctorat, Université de Provence, France.

[18] Aouachria, Z., Djoumati, D., Haddad, D. (2009). Theoretical analysis of the flow around a Savonius rotor. Proceedings of the Ninth International Conference on Thermal Engineering: Theory and Applications, Dhabi, UAE. Organizers: Ryerson University Dept of Mechanical Engineering.

[19] Nakjma, M., Iio, S., Ikeda, T. (2008). Performance of double step of savonius rotor for environmentally friendly hydraulic turbine. J. of Fl. Mechanics and Technology, 3(3): 410-419. http://doi.org/10.1299/jfst.3.410

[20] Peinke, J., Schaumann, P., Barth, S. (2007). Wind Energy: Proceedings of the Euromech Colloquium, Springer-Verlag Berlin Heidelberg. ISBN: 978-3-54033866-6. http://doi.org/10.1007/978-3-540-33866-6

[21] Dovgy, S., Kayan, V., Kochin, V. (2007). Experimental researches of characteristics of wind rotor models with vertical axis of rotation. In: Peinke J., Schaumann P., Barth S. (eds) Wind Energy. Springer, Berlin, Heidelberg. http://doi.org/10.1007/978-3-540-33866-6_33

[22] Montelpare, D'Alessandro, V., Zoppi, A., Ricci, R. (2017). Experimental study on a modified Savonius wind rotor for street lighting systems. Analysis of External Appendages and Elements, 144: 146-158. https://doi.org/10.1016/j.energy.2017.12.017

[23] Shikha, Bhatti, T.S., Kothari, D.P. (2005). Early development of modern vertical and horizontal axis wind turbines: A review. SAGE Journals, 29(3): 287-299. http://doi.org/10.1260/030952405774354859
[24] Mohamed, M.H., Janiga, G., Pap, E., Thévenin, D. (2011). Optimal blade shape of a modified Savonius turbine using an obstacle shielding the returning blade. Energy Conversion and Management, 52(1): 236-242. http://doi.org/10.1016/j.enconman.2010.06.070

[25] Sheldahl, R.E., Blacwell, B.F., Flitz, L.V. (1978). Wind tunnel performance data for two and three bucket Savonius rotor. Journal of Energy, 2(3): 160-164. http://dx.doi.org/10.2514/3.47966

[26] Akwa, J.V., Júnior, G.A.S., Petry, A.P. (2012). Discussion on the verification of the overlap ratio influence on performance coefficients of a Savonius wind rotor using CFD. Renewable Energy, 38(1): 141149. http://doi.org/10.1016/j.renene.2011.07.013

[27] Chauvin, A., Aouachria, Z., Tchifchiba, A. (1987). Etude Expérimentale de suspensions pour une éolienne Savonius. Revue Eolienne C.R.G.P. Rennes, Trim. II, pp. 35-39.

[28] Wang, Y.F., Zhan M.S. (2013). 3-Dimensional CFD simulation and analysis on performance of a micro-wind turbine resembling lotus in shape. Energy and Buildings, 65: 66-74. http://doi.org/10.1016/j.enbuild.2013.05.045

[29] Altana, B.D., Altana, G., Kovan, V. (2016). Investigation of $3 \mathrm{D}$ printed Savonius rotor performance. Renewable Energy, 99: 584-591. https://doi.org/10.1016/j.renene.2016.07.043

[30] Sheldahl, A.F., Blacwell, B. E., Flitz, L.V. (1978). Wind tunnel performance data for two and three bucket Savonius rotor. Journal of Energy, 2(3): 160-164. https://doi.org/10.2514/3.47966

[31] Becerra, M., Morán, J., Jerez, A., Cepeda, F., Valenzuela, M. (2017). Wind energy potential in Chile: Assessment of a small scale wind farm for residential clients. Energy Conversion and Management, 140: 71-90. https://doi.org/10.1016/j.enconman.2017.02.062

[32] Thierry, M.F., Drouet, V., Montagnier, O. (2017). Discrete vortex method for a detached flow on a twoairfoil configuration at high angle of attack. $52^{\text {nd }} 3 \mathrm{AF}$ International Conference on Applied Aerodynamics Progress in Flow Control, 3AF, Ecully, France.

[33] Darakananda, D., da Silva, A.F.C., Colonius, T., Eldredge, J.D. (2018). Data-assimilated low-order vortex modeling of separated flows. Phys. Rev. Fluids, 3(12): 124701. https://doi.org/10.1103/physrevfluids.3.124701

[34] Chauvin, A., Zeroual, A., Fraunie, P. (1986). Pressure measurements on a savonius rotor interpretations. European Wind Energy Association, Conference and Exhibition, Roma, Italy.

[35] Aouachria, Z., Belalmi, R., Tighaza, S., Lahlahi, M. (2019). New blade profile of VAWT: Experimental analysis. The First International Conference on Materials, Environment, Mechanical and Industrial Systems, Djelfa, Algeria. 